\title{
Objective testing for vasospasm in the hand-arm vibration syndrome
}

\author{
Judith A Allen, C C Doherty, S McGrann
}

\begin{abstract}
Since vibration white finger (VWF) became a prescribed industrial disease in 1985 , objective testing for the diagnosis and grading of the severity of the condition has become desirable. Measurements have been made of finger blood flow and finger systolic pressure before and after cold challenge in 22 healthy control subjects and 34 men presenting for medical examination in connection with compensation claims for VWF. This type of testing has previously produced one false negative result in 35 patients with an established clinical diagnosis of Raynaud's syndrome and no false positives in 40 control subjects. Finger blood flow was not significantly different in the claimants and controls in either warm or cool environments at local finger temperatures from $32^{\circ} \mathrm{C}$ down to $20^{\circ} \mathrm{C}$. Finger systolic pressure in the claimants was not significantly different from that in the controls when the fingers were warm at $32^{\circ} \mathrm{C}$. After five minutes middle phalangeal cooling to 15 or $10^{\circ} \mathrm{C}$, finger systolic pressure was $0 \mathrm{~mm} \mathrm{Hg}$ in 22 of the claimants indicating that vasospasm had occurred. No vasospasm occurred in the remaining 12 claimants or in any of the 22 control subjects. By clinical assessment alone, 26 of the 34 claimants had been thought to have VWF and $21(81 \%)$ of these exhibited vasospasm in the laboratory. Of the eight considered not to have VWF, only one exhibited vasospasm in the laboratory.
\end{abstract}

Raynaud's phenomenon can occur in workers who have used certain types of hand held vibrating tools for a period. ${ }^{1}$ This condition, known as vibration white finger (VWF), became a prescribed industrial

School of Biomedical Science, The Queen's University of Belfast, Medical Biology Centre, 97 Lisburn Road, Belfast BT9 7BL

J A Allen, S McGrann

Belfast City Hospital, Lisburn Road, Belfast BT9 7AB

C C Doherty disease in 1985 and since then the need for objective assessment has arisen.

A system of objective testing and grading of severity of vasospasm has already been described and evaluated in patients with Raynaud's syndrome of non-occupational origin. ${ }^{2}$ In the present study, this test system has been used to assess the presence or absence of vasospasm in the laboratory in a group of men presenting with compensation claims for VWF.

\section{Subjects and methods}

SUBJECTS

Thirty four men aged $27-73$ years (mean 54 years) presented for medical examination in connection with compensation claims for VWF. All gave a history of episodic cold induced blanching of the fingers. Duration of symptoms ranged from two months to 30 years (mean 12 years) and their use of vibrating tools varied from five to 43 years (mean 27 years). Table 1 shows their occupations. All patients underwent full clinical examination and were staged according to the Taylor-Pelmear scale ${ }^{3}$ before the laboratory visit. The clinical findings were not revealed to the laboratory investigator. Twenty five of the clinical assessments were made by the same physician (CCD); the remaining nine were made by three consultant surgeons also accustomed to assessing this condition. The clinical diagnosis of VWF was based on a clear history of symptoms consistent with digital vasospasm, exclusion of conditions known to cause secondary Raynaud's phenomenon, and an occupational history indicating prolonged use of tools recognised to cause VWF.

All the patients were investigated in the laboratory on two separate occasions, once in a temperature controlled chamber at $24^{\circ} \mathrm{C}$ (warm) and once at $20^{\circ} \mathrm{C}$ (cool). Measurements were also made on 22 men aged 22-72 years (mean 50 years) who had no circulatory

Table 1 Occupations of 34 claimants presenting with a history suggesting a diagnosis of $V W F$

\begin{tabular}{ll}
\hline Occupation & No of men \\
\hline Caulker & 22 \\
Riveter & 10 \\
Saw operator & 2 \\
\hline
\end{tabular}




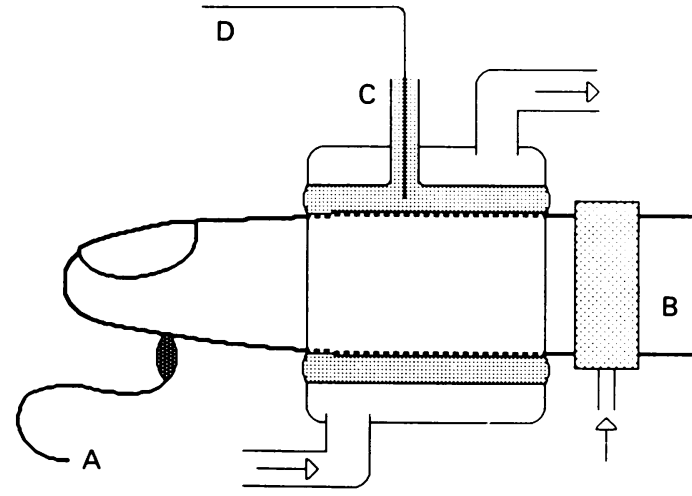

Figure 1 Method for middle phalangeal cooling and measurement of blood cell flux in fingertip skin. A Laser doppler probe; $B$ occlusion cuff on proximal phalanx; $C$ middle phalangeal cuff with perfused outer chamber and inner water filled chamber; $D$ thermocouple.

problems and no history of vibration exposure. Patients and control subjects wore only light clothing and reclined on a couch with the fingers supported at heart level. The investigations were approved by the local ethical committee and all subjects gave informed consent.

\section{FINGER BLOOD FLOW}

On each occasion, after a 30 minute equilibration period, finger blood flow was measured in one finger of each hand by venous occlusion plethysmography using fluid filled plethysmographs. ${ }^{4}$ The worst affected finger of each patient was chosen; if all were equally affected then the middle finger was used. Corresponding fingers were studied in the control subjects. Blood flow was measured over 10 minute periods at local finger temperatures of $32,30,27,24$, and $20^{\circ} \mathrm{C}$ and the fingers were then rewarmed for 15 minutes.

\section{FLUX IN FINGERTIP SKIN}

Provocative testing for vasospasm was then carried out. ${ }^{2}$ The technique used was a modification of the method described by Nielsen ${ }^{5}$ and is shown in fig 1 . A double lumen cuff surrounded the middle phalanx and the outer chamber of this was perfused by a chiller thermocirculatory pump. Thus fluid in the inner chamber around the finger could be kept constant at a particular temperature or rapidly altered as desired. An inflatable cuff surrounded the proximal phalanx and a laser doppler probe (Perimed PF3) was applied to the skin of the fingertip. This probe monitored blood cell flux in the superficial skin vessels and disappearance of flux during cooling was taken as an indication of vasospasm.

Initial flux measurements were made with the finger supported at mid-sternal level and maintained at
Table 2 Cooling stimuli for vasospasm

Day 1; comfortable room, $24^{\circ} \mathrm{C}$

1 Middle phalanx; $15^{\circ} \mathrm{C} \pm$ digital arterial occlusion for five minutes

2 Middle phalanx; $10^{\circ} \mathrm{C}+$ digital arterial occlusion for five minutes

$3 \mathrm{Cool}$ room to $16^{\circ} \mathrm{C}$ over 10 minutes and repeat step 2 .

Day 2; cool room, $20^{\circ} \mathrm{C}$

1 Middle phalanx; $15^{\circ} \mathrm{C}+$ digital arterial occlusion for five minutes

2 Middle phalanx; $10^{\circ} \mathrm{C}+$ digital arterial occlusion for five minutes

3 Middle phalanx: $10^{\circ} \mathrm{C}$

Hand cooled to $12^{\circ} \mathrm{C}$ by pre-cooled packs + digital arterial occlusion for five minutes.

$32^{\circ} \mathrm{C}$. Resting finger systolic pressure was measured by inflating the proximal cuff to a suprasystolic pressure which abolished flux and then slowly deflating it. The pressure at which flux suddenly reappeared was taken as resting finger systolic pressure. This measurement was repeated and the mean value calculated.

The middle phalanx of the finger was then rapidly cooled to either 15 or $10^{\circ} \mathrm{C}$ for five minutes with simultaneous inflation of the proximal cuff to prevent inflow of arterial blood warming the tissues. After five minutes cooling, finger systolic pressure was measured once more and then the finger was rewarmed to $32^{\circ} \mathrm{C}$. A finger systolic pressure of $0 \mathrm{~mm} \mathrm{Hg}$ after cooling indicated complete vasospasm. The amount of cooling required to induce vasospasm differed in different subjects, and table 2 summarises the standard cooling stimuli used. The severity of vasospasm in a particular subject was graded on the basis of the amount of cooling required to induce vasospasm (table 3 ).

\section{STATISTICS}

Statistical analysis was carried out using the Wilcoxon signed rank test.

\section{Results \\ CLINICAL ASSESSMENT}

On careful clinical assessment, 26 of the 34 claimants

Table 3 Grading of vasospasm on flux testing

\begin{tabular}{|c|c|c|}
\hline Test grade & Severity & Cooling to vasospasm \\
\hline 4 & Very severe & $\begin{array}{l}\text { Room, } 24^{\circ} \mathrm{C} \text {; finger, } 15^{\circ} \mathrm{C} \text {; no } \\
\text { occlusion }\end{array}$ \\
\hline 3 & Severe & $\begin{array}{l}\text { Room, } 24^{\circ} \mathrm{C} \text {; finger, } 15^{\circ} \mathrm{C} \text {; occlusion } \\
\text { for five minutes }\end{array}$ \\
\hline 2 & Moderate & $\begin{array}{l}\text { Room, } 24 \text { or } 20^{\circ} \mathrm{C} \text {; finger, } 10^{\circ} \mathrm{C} \text {; } \\
\text { occlusion for five minutes } \pm \text { cool } \\
\text { room to } 16^{\circ} \mathrm{C}\end{array}$ \\
\hline 1 & Mild & $\begin{array}{l}\text { Room, } 20^{\circ} \mathrm{C} \text {; finger, } 10^{\circ} \mathrm{C} \text {; occlusion } \\
\text { for five minutes }+ \text { cool hand }\end{array}$ \\
\hline 0 & Negative & $\begin{array}{l}\text { No vasospasm induced by any of } \\
\text { the above stimuli }\end{array}$ \\
\hline
\end{tabular}




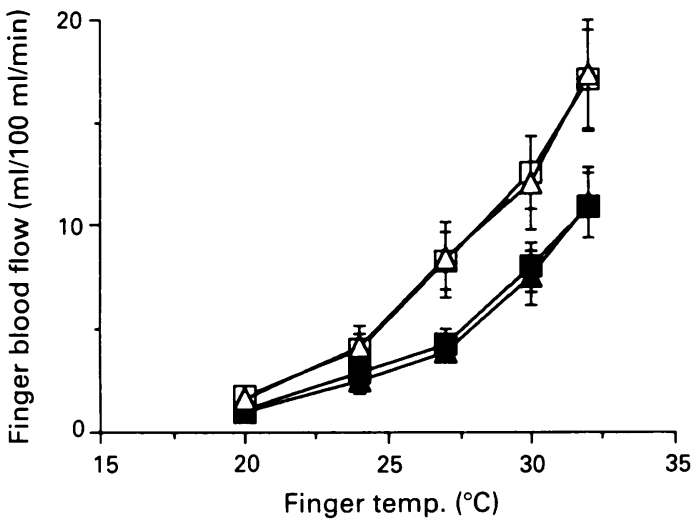

Figure 2 Finger blood flow (mean, $S D$ ) at local finger temperatures from $32^{\circ} \mathrm{C}$ to $20^{\circ} \mathrm{C}$ in 22 men with a history of $V W F$ who exhibited vasospasm in the laboratory and their matched controls; $\square$ control right fingers; $\triangle$ control left fingers; $\square W F$ right fingers; $\Delta V W F$ left fingers.

were thought to have VWF, the severity of their condition varying from grade I to grade III on the Taylor-Pelmear scale.

\section{FINGER BLOOD FLOW}

Figure 2 shows finger blood flow over a range of local finger temperatures in the worst affected finger of each hand of the 22 men with VWF who exhibited vasospasm in the laboratory and their matched controls. Finger blood flow decreased in both groups as finger temperature decreased but there was no significant difference between the blood flow in the VWF fingers and the control fingers at any particular temperature. There was a wide variation in resting finger blood flow at any particular local finger temperature in both the control group and the VWF group. When the fingers were warm at $32^{\circ} \mathrm{C}$ flow ranged from 45.2 to $2.8 \mathrm{ml} / 100 \mathrm{ml} / \mathrm{min}$ in the control fingers and from 33.5 to $1.2 \mathrm{ml} / 100 \mathrm{ml} / \mathrm{min}$ in the VWF fingers. When the fingers were cold at $20^{\circ} \mathrm{C}$, flow in the control fingers varied from 4.0 to $0.2 \mathrm{ml} /$ $100 \mathrm{ml} / \mathrm{min}$ and in the VWF fingers from 3.8 to 0.0 .

\section{FLUX IN FINGERTIP SKIN}

Figure 3 shows measurements of resting finger systolic pressure in both index fingers of a 34 year old man who had been a riveter in an aircraft factory for five years. Over the previous two years he had experienced increasing coldness, whiteness, and numbness in the fingers of his left hand in the cold. He had no problems in his right hand. The middle phalanx in each finger is at $32^{\circ} \mathrm{C}$ (top trace). Cuff pressure (middle trace) is initially $0 \mathrm{~mm} \mathrm{Hg}$ and there is obvious flux in both fingertips (bottom trace). Inflation of the proximal cuffs to $150 \mathrm{~mm} \mathrm{Hg}$ at $\mathbf{A}$ abolishes flux in both finger tips, but as the cuffs are gradually deflated, commencing at $\mathbf{B}$, flux suddenly returns at a cuff pressure of $117 \mathrm{~mm} \mathrm{Hg}$ in the right index finger and $120 \mathrm{~mm} \mathrm{Hg}$ in the left. These pressures are the resting finger systolic pressures.

Figure 4 shows flux measurements from the same fingers after five minutes cooling to $10^{\circ} \mathrm{C}$. The top two traces show middle phalangeal temperature and proximal cuff pressure as before, the third trace is the flux recording from the skin of the right fingertip and the bottom record is flux in the left fingertip skin. When the fingers are warm at $32^{\circ} \mathrm{C}$, flux is present in

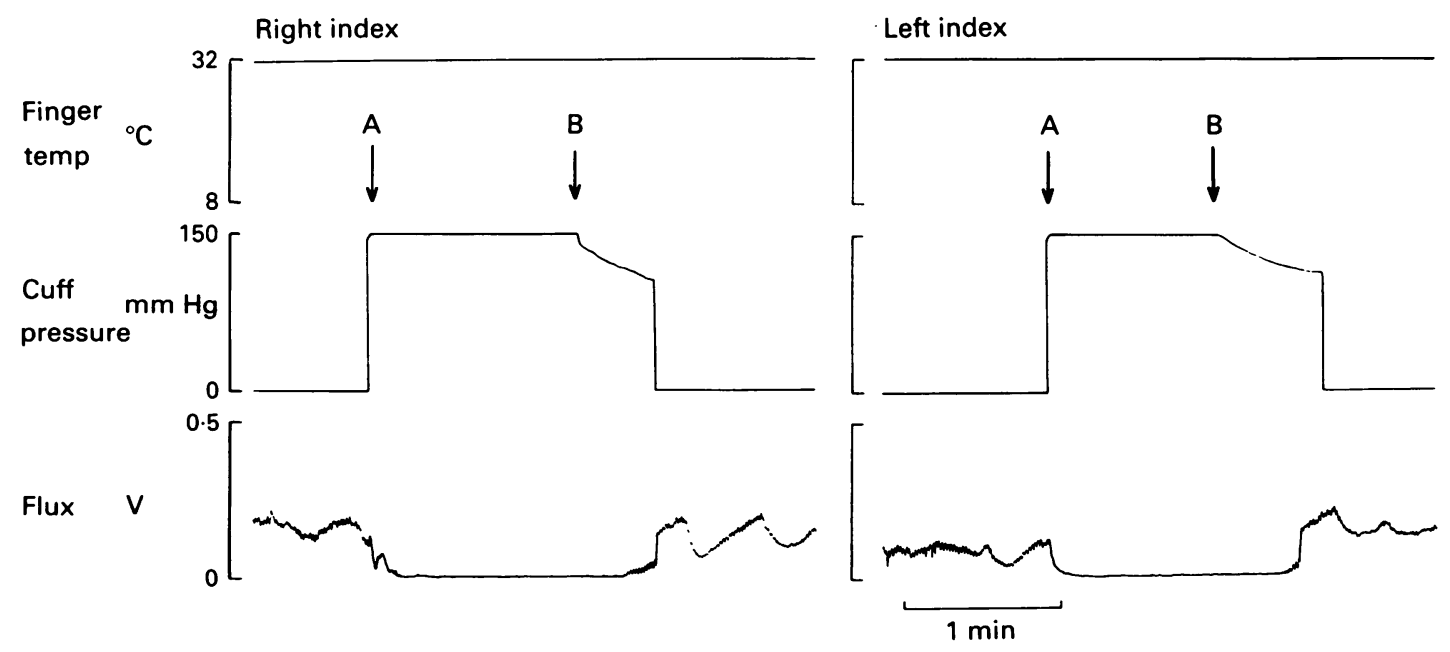

Figure 3 Measurement of resting FSP in the index fingers of a 34 year old riveter who has vasospastic symptoms only in his left hand. The top trace shows the temperature around the middle phalanx. The middle trace show shows the pressure in the cuff on the proximal phalanx. The bottom trace shows the flux in the fingertip skin. At A the cuff is inflated to $150 \mathrm{~mm} \mathrm{Hg}$. At B the cuff is gradually deflated. The pressure at which flux returns is FSP. 


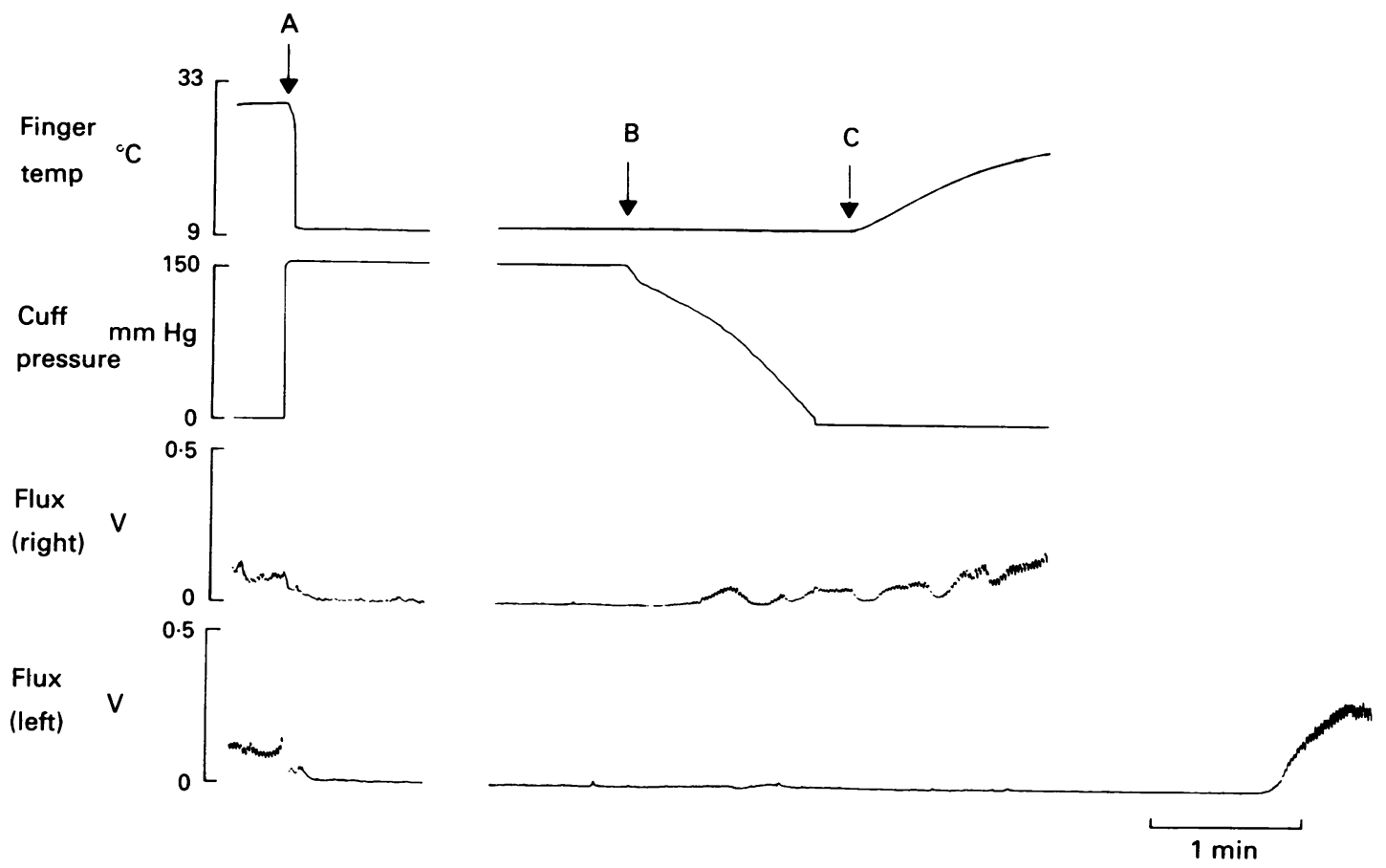

Figure 4 Flux recordings from the index fingers of the same patient as shown in fig 3. The top trace shows temperature around the middle phalanx. The second trace shows the pressure in the proximal cuff. The third trace shows the flux in the fingertip skin of the right index finger (no vasospastic symptoms), and the bottom trace shows flux in the left index finger (moderately severe vasospastic symptoms). At $A$ the middle phalanx was cooled from 32 to $10^{\circ} \mathrm{C}$ with arterial occlusion. At B gradual deflation of the occluding cuff commenced. Rewarming of the middle phalanx started at $C$.

both fingers. At $\mathbf{A}$ the middle phalanges were suddenly cooled to $10^{\circ} \mathrm{C}$ with simultaneous digital arterial occlusion. This abolishes flux in both fingertips. After five minutes, at $\mathbf{B}$, with the middle phalanges still kept cold, the proximal cuff is gradually deflated. Flux returns in the right index finger at a pressure of $123 \mathrm{~mm} \mathrm{Hg}$, which is similar to resting finger systolic pressure at $32^{\circ} \mathrm{C}$ (fig 2). So cooling has not produced vasospasm in this finger. In the left index finger there is no return of flux as the pressure cuff is deflated. Even at complete deflation flux is absent-finger systolic pressure after cooling is $0 \mathrm{~mm} \mathrm{Hg}$ and there is total vasospasm. Reheating of the middle phalanx was started at $\mathbf{C}$ and almost three minutes of rewarming of the middle phalanx was required before flux returned.

During each visit the standard cooling stimuli (table 2) were applied in turn until vasospasm was induced and the severity of the vasospastic condition was graded (table 3). It was not possible to induce vasospasm in the laboratory in 12 of the 34 men with a history of VWF. None of the 22 control subjects exhibited vasospasm in the laboratory even after the most severe cooling stress.

The clinical diagnoses indicated that of the 34 patients referred for medicolegal assessment, 26 had VWF. Of these 26 , laboratory testing gave positive results in $21(81 \%)$ suggesting that false positive clinical diagnoses could have been made in five patients. Of the eight thought not to have VWF on clinical grounds, testing gave negative results in seven, and a low grade positive result in one subject,

Table 4 Comparison of clinical grading on the TaylorPelmear scale and flux test grading in 34 claimants with a history of $V W F$

\begin{tabular}{lcl}
\hline Clinical grade & No of patients & Flux test grade \\
\hline IV & 0 & Grade 4: 0 patients \\
III & 11 & $\begin{array}{l}\text { Grade 3: 6 patients } \\
\text { Grade 2: 1 patient }\end{array}$ \\
II-III & & $\begin{array}{l}\text { Grade 1: 1 patient } \\
\text { Grade 0: 3 patients }\end{array}$ \\
II & 4 & $\begin{array}{l}\text { Grade 2: 2 patients } \\
\text { Grade 1: 2 patients }\end{array}$ \\
I-II & 7 & $\begin{array}{l}\text { Grade 2: 2 patients } \\
\text { Grade 1: 3 patients }\end{array}$ \\
I & & Grade 0: 2 patients \\
0 & 3 & Grade 2: 1 patient \\
& 1 & Grade 1: 2 patients \\
\hline
\end{tabular}


Table 5 Severity of the vasospastic condition in 34 claimants with a history of $V W F$ and 35 patients with Raynaud's syndrome of non-occupational origin

\begin{tabular}{lcc}
\hline Test grade & No of VWF claimants & No of Raynaud's patients \\
\hline 4 & 0 & 5 \\
3 & 6 & 12 \\
2 & 6 & 14 \\
1 & 9 & 3 \\
0 & 13 & 1 \\
\hline
\end{tabular}

possibly representing one false negative clinical diagnosis in a patient with an early stage of VWF. Table 4 compares the clinical grading of severity with the flux test grading. There was a significant correlation between the two $(r=0.6, p<0.001)$.

Table 5 shows the severity of the vasospastic condition as determined by flux test grading in the 34 men whose clinical history suggested VWF. The gradings for 35 patients who presented over the same period of time with non-occupational Raynaud's phenomenon ${ }^{2}$ are included for comparison. Vasospasm appeared to be less severe in the men with VWF despite their greater age (table 6). There was no correlation $(r=0.246)$ between the severity of the vasospastic condition in the patients with VWF and the duration of their vibration exposure, which varied from five to 43 years (mean 27 years).

\section{Discussion}

Attempts to develop reliable objective testing for VWF have involved many different techniques for measurement of circulatory recovery time after a standard cold challenge $e^{6-8}$ or detection of vasospasm after provocative cooling tests. ${ }^{59-11}$

The cold provocation test used in this study was developed as a modification of the method described by Nielsen ${ }^{5}$ but uses a laser doppler probe rather than a strain gauge for the measurement of finger systolic pressure. Thus measurements are being made in the skin blood vessels only as the laser beam penetrates no further than 1.0 to $1.5 \mathrm{~mm}$. The test has been shown to be accurate in confirming the diagnosis of Raynaud's phenomenon in patients with an established clinical diagnosis of vasospastic disease of nonoccupational origin. ${ }^{2}$ In 35 patients there was one

Table 6 Age distribution of 34 men with a history of VWF and 35 patients with Raynaud's syndrome of nonoccupational origin

\begin{tabular}{ccl}
\hline Age range (y) & 33 with VWF & 34 with Raynaud's phenomenon \\
\hline $10-19$ & 0 & 3 \\
$20-29$ & 2 & 5 \\
$30-39$ & 5 & 8 \\
$40-49$ & 4 & 8 \\
$50-59$ & 6 & 7 \\
$60-69$ & 14 & 3 \\
$\geqslant 70$ & 2 & 0 \\
\hline
\end{tabular}

false negative result and in 40 control subjects there were no false positive results. The test is therefore both specific and fairly sensitive, possibly failing to diagnose very early or very mild disease.

It has now been used to study 34 men presenting with compensation claims for vibration white finger. All gave a history of symptoms affecting their fingers but after careful clinical assessment 26 were thought to have vasospastic disease and eight were not. There was good agreement between this clinical diagnosis and flux testing, but five of the 26 did not exhibit vasospasm in the laboratory, and one of the eight had vasospasm after cooling tests in the laboratory.

Good agreement also existed between the clinical grading on the Taylor-Pelmear scale and flux test grading of severity although the second tended to downgrade severity in the various clinical groupings and the correlation coefficient of 0.6 was not as close as that of 0.75 seen in a study of 35 patients with nonoccupational Raynaud's syndrome.

A surprising finding was that the severity of vasospasm detected in the laboratory did not correlate well with the duration of occupational vibration exposure. This is contrary to some other reports. ${ }^{12}{ }^{13}$ It has to be remembered, however, that in the present study the men were tested when they presented in connection with compensation claims for VWF and they had not all experienced the same type of occupational vibration. The study was concerned with determining the possible usefulness of this type of testing in assessment rather than with measuring the effects of a particular type of vibration on the circulation.

The 34 men with VWF studied appeared to have less severe vasospastic disease-as judged by this method-than 35 patients with non-occupational Raynaud's syndrome who presented over the same period of time. Although the populations were small, both groups were studied as they presented and not selected in any way except for the history of finger symptoms. Therefore the results tend to suggest that in subjects with VWF, even after years of vibration exposure, the severity of vasospasm as measured by this laboratory technique may be less than that in Raynaud's of other aetiology. This finding may not be applicable to occupations other than those studied here, however, although some other occupational surveys have also shown only small numbers of men with severe disease (grades III and IV). ${ }^{14-17}$

An interesting but unanswered question remains from this study and other surveys ${ }^{17}$ - why do some workers develop vasospastic problems after a relatively short period of occupational vibration exposure whereas others do not have any problems even after at least 30 years exposure?

Because resting hand blood flow has been shown to be lower in patients with Raynaud's disease than in normal subjects, ${ }^{18}$ finger blood flow was measured in 
the VWF claimants who exhibited vasospasm in the laboratory. It was not significantly different from that in their matched control subjects indicating that this measurement is probably not helpful in the objective assessment of these patients. Despite the equilibration period and the careful control of both general environmental temperature and local finger temperature, flow varied considerably from patient to patient and from control subject to control subject. Thus the resting level of finger blood flow in a particular subject does not contribute to the diagnosis.

In conclusion, this type of objective testing for cold induced vasospasm may be helpful in the assessment of patients presenting for examination in connection with claims for VWF. Furthermore, repeated testing at intervals might help in the early detection of this condition and contribute to our understanding of the mechanisms involved.

We thank the Health and Safety Agency for Northern Ireland and Dr J G Hall, Employment Medical Advisory Service for their support.

1 Taylor W. The hand-arm vibration syndrome (HAVS) secondary Raynaud's phenomenon of occupational origin. Proceedings of the Royal College of Physicians of Edinburgh 1989;19: $7-13$.

2 Allen JA, Devlin MA, McGrann S, Doherty CC. An objective test for the diagnosis and grading of vasospasm in patients with Raynaud's syndrome. Clin Sci (in press).

3 Taylor W, Pelmear PL. In: Taylor W, Pelmear PL, eds. Vibration white finger in industry. London: Academic Press, 1975:xxi.

4 McGrann S, Irwin ST, Allen JA. A plethysmograph for the measurement of digital blood flow. J Med Eng Technol 1986; 10:329-31.

5 Nielsen SL. Raynaud phenomena and finger systolic pressure during cooling. Scand J Clin Lab Invest 1978;38:765-70.

6 Porter JM, Snider RL, Bardana EJ, Rosch J, Eidemiller LR. The diagnosis and treatment of Raynaud's phenomenon. Surgery 1975;77:11-23.

7 Welsh CL. Digital rewarming time in the assessment of vibration-induced white finger. Scand $J$ Work Environ Health 1986;12:249-50.

8 Juul C, Nielsen SL. Locally induced digital vasospasm detected by delayed rewarming in Raynaud's phenomenon of occupational origin. Br J Ind Med 1981;38:87-90.

9 Olsen N, Nielsen SL. Diagnosis of Raynaud's phenomenon in quarrymen's traumatic vasospastic disease. Scand J Work Environ Health 1979;5:249-56.

10 Ekenvall $L$, Lindblad LE. Vibration white finger and digital systolic pressure during cooling. Br J Ind Med 1986;43:280-3.

11 Krahenbuhl B, Nielsen SL, Lassen NA. Closure of digital arteries in high vascular tone states as demonstrated by measurement of systolic blood pressure in the fingers. Scand J Clin Lab Invest 1977;37:71-6.

12 Miyashita $\mathrm{K}$, Shiomi S, Itoh $\mathrm{N}$, Kasamatsu $\mathrm{T}$, Iwata $\mathrm{H}$. Epidemiological study of vibration syndrome in response to total hand-tool operating time. Br J Ind Med 1983;40:92-8.

13 Taylor W, Pelmear PL, Pearson JCG. Vibration induced white finger epidemiology. In: Taylor W, Pelmear PL, eds. Vibration white finger in industry. London: Academic Press, 1975:1-13.

14 Engstrom K, Dandanell R. Exposure conditions and Raynaud's phenomenon among riveters in the aircraft industry. Scand $J$ Work Environ Health 1986;12:293-5.

15 Behrens V, Taylor W, Wasserman DE. Vibration syndrome in workers using pneumatic chipping and grinding tools. In: Taylor W, Brammer AJ, ed. Vibration effects on the hand and arm in industry. New York: John Wiley, 1982:147-55.

16 Saito K. Prevention of the hand arm vibration syndrome. Scand $J$ Work Environ Health 1987;13:301-4.

17 Ashe WF, Cook WT, Old JW. Raynaud's phenomenon of occupational origin. Arch Environ Health 1962;5:333-43.

18 Peacock JH. A comparative study of the digital cutaneous temperatures and hand blood flows in the normal hand, primary Raynaud's disease and primary acrocyanosis. Clin Sci 1959;18:25-33.

Accepted 13 January 1992 